\title{
IMPACTOS DO GEOTURISMO NOS ATRATIVOS NATURAIS DAS ÁGUAS DO POLO TURÍSTICO DAS ÁGUAS DE SÃO LOURENÇO, MT.
}

\section{Laís Paciência GODOY ${ }^{1}$, Fabiano Tomazini da CONCEIÇÃO ${ }^{2}$, Antonio Misson GODOY ${ }^{3}$, Larissa Marques Barbosa de ARAÚJO ${ }^{4}$}

\author{
(1) Programa de Pós-Graduação em Geociências - IGCE- UNESP- Univ. Estadual Paulista. Endereço eletrônico:
}

lais_godoy@hotmail.com

(2) Depto de Planejamento Territorial e Geoprocessamento - IGCE- UNESP- Univ. Estadual Paulista. Endereço eletrônico: ftomazini@rc.unesp.br

(3) Departamento de Petrologia e Metalogenia - IGCE- UNESP- Univ. Estadual Paulista. Endereço eletrônico: mgodoy@rc.unesp.br (4) Av. 24A, 15151-Bela Vista, CEP. 13 506-900-Rio Claro (SP), Brasil. Univ. Federal de Uberlândia-UFU. Rod. MG Km 01, nº 746, CEP: 38500-000-Monte Carmelo-MG. Endereço eletrônico: larissamarquesba@ gmail.com

\author{
Introdução \\ Ecoturismo/Geoturismo \\ Impacto Ambiental nos Atrativos Turísticos \\ Localização da área \\ Histórico das Águas Termais \\ Método de Estudo \\ Caracterização da Área \\ Potencial Turístico e Avaliação dos Impactos \\ Recomendações \\ Referências Bibliográficas
}

\begin{abstract}
RESUMO - As águas termais do Polo Turístico das Águas de São Lourenço ocorrem nos municípios de São Vicente, Juscimeira e Jaciara, sudeste do Estado do Mato Grosso, a 150km de Cuiabá. O trabalho visa a geração de informações na área das Geociências que possam apoiar o geoturismo da região, baseado principalmente nos recursos hídricos de águas minerais, termais e superficiais, além de propor soluções a partir do levantamento do potencial turístico dos atrativos municipais e contribuir para a elaboração de um "Geoparque" para a área. Os impactos decorrentes das atividades turísticas foram avaliados mediante aplicações dos métodos VIM (Visitor Impact Management) e PER (Pressão-Estado-Resposta), com ênfase em indicadores biofísicos. As características geológicas e hídricas da região contribuíram com a ocorrência do hidrotermalismo, presença de serras e cavernas e inúmeras cachoeiras e corredeiras, com possibilidades para a prática do turismo contemplativo, geoturismo e ecoturismo. A estância hidromineral constitui um importante polo turístico e os municípios sobrevivem economicamente da atividade turística, que depende da infiltração da água da chuva para renovação do principal produto, o manancial superficial e termal. Dessa forma, manter esse patrimônio significa verificar as consequências e os benefícios do turismo baseado na apropriação e exploração deste bem tão essencial para a economia da região.
\end{abstract}

Palavras-chave: Águas Termais, São Lourenço, Mato Grosso, Geoparque.

\begin{abstract}
Thermal waters of the Águas de São Lourenço Touristic Pole occur in the municipalities of São Vicente, Juscimeira and Jaciara, southeastern Mato Grosso state, $150 \mathrm{~km}$ far from Cuiabá. This paper aimed to generate information in the field of geoscience to support geotourism in the region based mainly on thermal and surface mineral water resources, as well as propose solutions from a survey of tourism potential of local attractions and to consider solutions that contribute to the elaboration of a "Geopark" in the region. The impact of tourism activities were evaluated by applying the VIM (Visitor Impact Management) and PSR (Pressure-State-Response), methods with emphasis on biophysical indicators. The geological and hydric characteristics contributed to the hydrothermal, presence of mountains and caves and numerous waterfalls and rapids, with immense possibilities for the practice of contemplative tourism and ecotourism. The hidromineral resort is a major tourist pole and the municipalities survive economically on tourism activities, which depend on the infiltration of rainwater for renovation of the main product, surface sources and thermal springs. Thus, keeping this heritage means to contribute checking the consequences and benefits of tourism based on ownership and exploitation so essential to the region's economy.
\end{abstract}

Keywords: Thermal Waters, São Lourenço, Mato Grosso, Geopark

\section{INTRODUÇÃO}

A água representa insumo fundamental à vida, configurando elemento insubstituível em diversas atividades humanas, além de manter o equilíbrio do meio ambiente. A ideia de abundância serviu durante muito tempo como suporte à cultura do desperdício da água disponível, a sua pouca valorização como recurso e ao adiamento dos investimentos necessários à otimização de seu uso.

$\mathrm{O}$ acelerado crescimento populacional conduz ao aumento localizado de demanda, a partir da intensa urbanização, industrialização e expansão agrícola, da degradação da qualidade das águas e, a má utilização destes recursos vem ocasionando, em várias regiões, problemas de escassez e/ou uma redução substancial deste importante bem mineral.

As informações dos recursos hídricos visam coletar dados que permitam avaliar e gerar informações que possibilitem orientar e 
fomentar sua exploração racional dirigida, por exemplo o desenvolvimento de hotéis, pousadas, balneários e indústrias.

A partir dos princípios de ecoturismo e geoturismo é que este trabalho se direciona à obtenção das informações de apoio ao turismo associado aos recursos hídricos, além de contribuir para a identificação dos impactos do uso público nestes atrativos turísticos da região do Polo Turístico das Águas Superficiais, Minerais e Termais de São Lourenço - MT, na região sudeste do Estado de Mato Grosso, região de São Vicente, Jaciara, Juscimeira e municípios no seu entorno.

As características geológicas e hídricas da região contribuíram com a ocorrência de hidrotermalismo, confinado aos sedimentos arenosos da Formação Furnas, e para que a região apresentasse feições geomorfológicas exuberantes registradas pela presença de serras e cavernas.

Os variados recursos hídricos superficiais da região resultam em inúmeras cachoeiras e corredeiras, com imensas possibilidades para a prática do turismo contemplativo, geoturismo e ecoturismo.

O turismo ocorreu, na última década, como um grande elemento de modificação na região, aumentando o fluxo de pessoas, as construções de empreendimentos ligados ao setor das águas minerais e termais, a geração de emprego e renda, e os impactos positivos e negativos associados.

Este trabalho apresenta como suporte à integração, tratamento e interpretação das informações de cunhos geológicos, hidrogeológicos, geomorfológicos, turísticos e gerenciais, tendo como enfoque o campo de recursos hídricos. Associado a estes objetivos, visa-se investigar o potencial do geoturismo como ferramenta de divulgação de conhecimentos geocientíficos, destacando neste trabalho principalmente as informações geológicas.

A partir destas informações, será possível promover e reconhecer propostas de melhor uso e adequações das atrações turísticas locais e regionais, permitindo intensificar todas as etapas de desenvolvimento do turismo como um empreendimento que envolva toda a sociedade daquela região, abordando desde o reconhecimento das atrações, passando pelos vários sistemas administrativos, socioeconômicos e de legislação associados ao tema.

Paralelamente, foi elaborado um inventário com os principais pontos turísticos, inclusive com documentação fotográfica, que, trabalhados adequadamente, poderão incrementar o fluxo de turistas. A partir destas informações será possível desenvolver um turismo integrado a um sistema de aproveitamento das águas minerais e termais. Mas, para que se atinja esse ideal é fundamental que haja organização, infraestrutura adequada, educação aos visitantes e conscientização de todos para a importância de se manter os níveis sustentáveis de uso dos espaços naturais, bem como mecanismos de redução de impactos ambientais e resíduos gerados pelo ser humano.

A aplicação dos princípios orientadores das informações das águas deverá ordenar seu uso múltiplo e possibilitar sua preservação para as futuras gerações, minimizando e evitando os problemas decorrentes da escassez e da poluição dos cursos de água, os quais afetam e comprometem os usos dos recursos hídricos.

Deste modo, o presente trabalho contribuirá para a conscientização e o maior envolvimento da sociedade nos debates e processos decisórios relativos à gestão dos recursos hídricos desta estância hidromineral, onde os municípios sobrevivem economicamente da atividade turística, que depende da infiltração da água da chuva para renovação do principal produto dos municípios, o manancial superficial e termal.

\section{ECOTURISMO/GEOTURISMO}

O ecoturismo segundo a EMBRATUR (2008) é um segmento da atividade turística que utiliza de forma sustentável o patrimônio natural ou cultural, incentiva sua conservação e busca a formatação de uma consciência ambientalista, promovendo o bem estar das populações.

Segundo The International Ecotourism Society (TIES, 2005), considera-se ecoturismo como a "viagem responsável para áreas naturais que conservem o ambiente e melhorem o bem estar das populações locais" e que 
permitam criar condições que fomentem a sustentabilidade, incluindo o homem e suas ações como delimitadoras de ações sustentáveis.

Sardinha et al. (2007) entendem o turismo ecológico/rural como um segmento da atividade turística que utiliza o patrimônio natural e cultural de forma responsável, incentiva sua conservação e busca a formação de uma consciência ambientalista da população envolvida.

Portanto, o ecoturismo seria toda a atividade turística realizada em área natural com o objetivo de observação, conhecimento e contato com paisagens, atrações ambientais, ricas em água e elementos bióticos da flora e fauna, bem como dos aspectos cênicos, com ou sem sentido de aventura, prática de esportes e realização de pesquisas científicas. Surge, portanto, como uma tendência natural no ser humano, em contraste com o seu cotidiano urbano.

Entretanto, esse conceito mostra-se parcialmente limitado por não incluir as ações e interferências antrópicas no meio visitado, pois com a crescente busca pela sustentabilidade, se exige incluir e limitar os efeitos desta no meio visitado.

O geoturismo foi oficialmente e academicamente conceituado por Hose (1997), que o definiu como a "atividade de prover subsídios que possibilitem aos turistas adquirir o conhecimento necessário para compreender a geologia e geomorfologia de um local, além da apreciação de sua beleza cênica".

Hose (2000) propôs ajustes no conceito de geoturismo, alterando sua definição para $a$ "provisão de facilidades interpretativas e serviços para promover o valor e os benefícios sociais de lugares, materiais geológicos $e$ geomorfológicos e assegurar sua conservação, para uso de estudantes, turistas e outras pessoas com interesse recreativo ou de lazer".

A Travel Industry Association of America (TIAA, 2003) definiu geoturismo como o "turismo que se apoia ou valoriza as características geográficas do lugar em foco, incluindo-se o meio ambiente, cultura local, a herança estética e o bem-estar da população local".

\section{IMPACTO AMBIENTAL NOS ATRATIVOS TURÍSTICOS}

Com relação ao termo impacto ambiental, vale destacar o Artigo $1^{\circ}$ da Resolução CONAMA $n^{\circ} 1$ (CONAMA, 1986), que define impacto como a alteração das propriedades físicas, químicas e biológicas do meio ambiente, provocada por qualquer forma de matéria ou energia, resultante direta ou indiretamente de atividades humanas e que afetem: a saúde, a segurança e o bem-estar da população; as atividades sociais e econômicas; a biota e a qualidade dos recursos ambientais e as condições estéticas ou sanitárias do meio ambiente.

De acordo, com a Resolução CONAMA ${ }^{\circ}$ 237 (CONAMA, 1997), as atividades turísticas (complexos turísticos e de lazer) devem possuir as devidas licenças ambientais prévia, de instalação e de operação, pois elas podem gerar impactos ambientais devido ao tamanho do empreendimento.

Com relação aos impactos ocorridos pelo uso e ocupação dos solos, a área afetada pela exploração turística pode, muitas vezes, apresentar sérios problemas, segundo Jones
(1993), Cole (1993) e Magro (1999, 2001), tais como: impermeabilização excessiva do solo; erosão e eliminação da vegetação protetora; contaminação do solo e do lençol freático por disposição inadequada de resíduos sólidos (domésticos, industriais, hospitalares e agrícolas); compactação para a construção de estradas e urbanização; acumulação de lixo no acesso e no próprio âmbito das atrações naturais; alargamento das trilhas, pisoteio de vegetação nos caminhos; coleta ou danos de: vegetação, rochas e minerais recolhidos como souvenires; danificação de paredes rochosas ou vegetação pela inserção de marcas, pinturas e outras rasuras.

Segundo Kuss et al. (1990) e Midaglia (1994), nos recursos hídrico, os impactos mais comuns são apresentados pelo consumo não sustentável da água e, a contaminação dos mananciais e aquíferos por despejos de efluentes domésticos sem o prévio tratamento ou pela agroindústria.

Segundo, Cole (1993) e Hammitt \& Cole (1998) a fauna, flora e ecossistemas também 
são os que sofrem impactos devido às atividades turísticas, provocando, na maioria das vezes, a eliminação ou a modificação da cobertura vegetal da região, afetando ambientes frágeis e causando a fragmentação da vegetação nativa, dificultando a reprodução dos animais e vegetais com a eliminação do ecossistema encontrado na região.

Dentre os impactos positivos, além daqueles de ordem econômica (empregos, impostos, taxas e consumo), têm sido destacados, também, a criação de programas de proteção à fauna e à flora, campanhas preservacionistas, fiscalização do uso turístico e os guias dos passeios turísticos são na maioria atividades praticadas pelas comunidades receptoras de atividade turística (Ruschmann, 2002).

A partir da década de 70, muitos métodos foram utilizados para avaliar e quantificar os impactos provenientes das atividades turísticas relacionadas aos atrativos turísticos naturais de uma região, tais como: LAC - Limits of Acceptable Change (Stankey et al., 1985), VIM - Visor Impact Manegament (Graefe et al., 1990), Capacidade de Carga (Cifuentes, 1992), PER - Pressão-Estado-Resposta (OECD, 1994) e VERP - Visitor Experience and resource Protection (NPS, 1995).

\section{LOCALIZAÇÃO DA ÁREA}

O circuito das águas do Polo Turístico das Águas de São Lourenço é constituído pelas águas termais e os recursos hídricos, localizados principalmente na Bacia Hidrográfica do Rio São Lourenço, além das ocorrências fontes de Poxoréo e Primavera do Leste, e das fontes associadas ao Batólito Granítico de São Vicente.

A área estudada está localizada na região centro-oeste do Brasil, região sudeste do Estado de Mato Grosso, a $150 \mathrm{~km}$ de Cuiabá. Geograficamente, a área enquadra-se na mesorregião 130, microrregião 538 Rondonópolis.
As águas termais e os recursos hídricos superficiais e profundos do circuito do Polo Turístico das Águas de São Lourenço estão situados principalmente na localidade de São Vicente e na Bacia Hidrográfica do Rio São Lourenço (Figura 1). A região principal das ocorrências estudadas localiza-se nos municípios de (1) Santo Antonio do Leverger, (distrito de São Vicente), (2) Jaciara, (3) São Pedro da Cipa e (4) Juscimeira, (5) distrito de Santa Elvira. Os municípios são cortados pela BR-364 entre as cidades de Cuiabá e Rondonópolis e a BR 070 entre São Vicente e Primavera do Oeste.

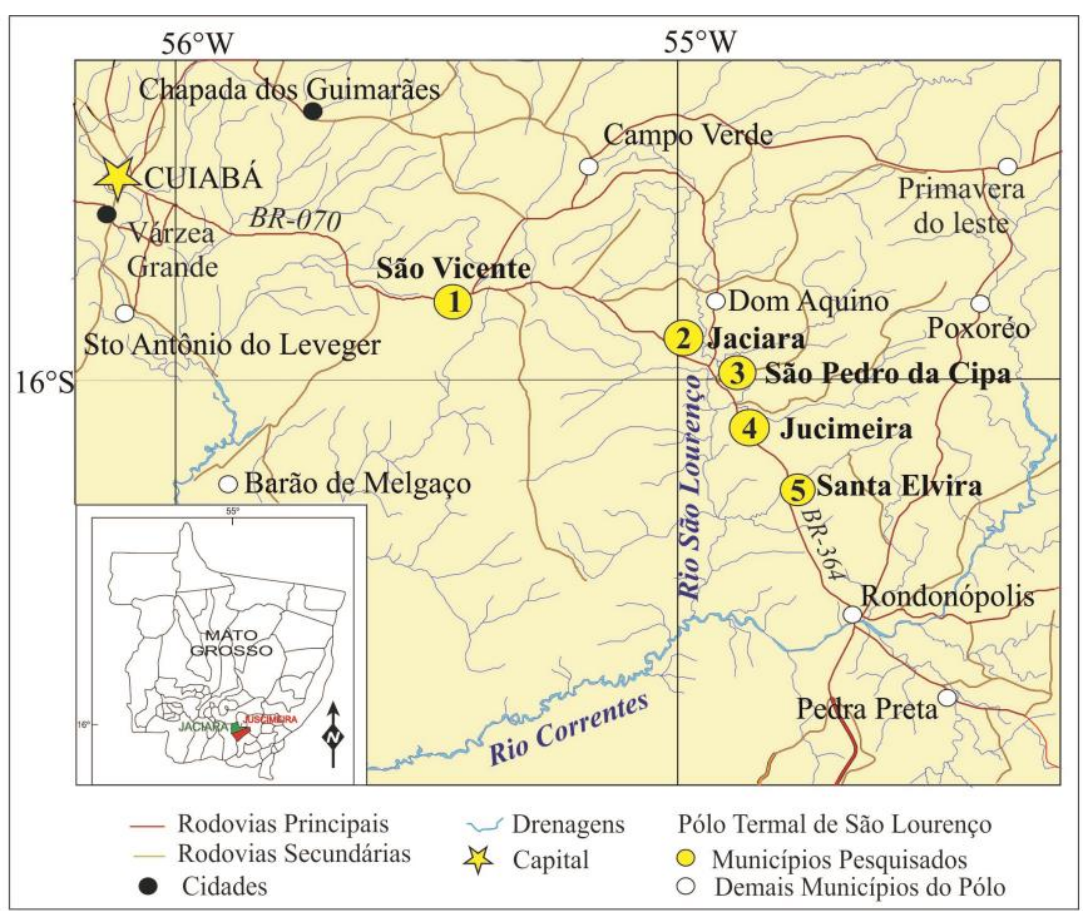

Figura 1. Mapa de drenagem, de localização e de via de acesso à região do Polo Termal de São Lourenço, sudeste do Estado de Mato Grosso (Lacerda et al. 2004). 


\section{HISTÓRICO DAS ÁGUAS TERMAIS}

O Instituto Histórico e Geográphico do Rio de Janeiro em publicações de 1826 (Corrêa Netto, 1920) descreve as primeiras referências sobre as fontes termais do Estado de Mato Grosso, as "Fontes Termais de Palmeiras", que se encontram situadas no Granito São Vicente, próximo à Fazenda Palmeiras, à margem e no leito do córrego dos Veados ou Águas Quentes.

No texto do "Annaes Brasilienses de Medicina", publicado em 1852 (Corrêa Netto, 1920), foram descritas para o Estado do Mato Grosso, as ocorrências de águas termais e, que as suas nascentes estão associadas a granitos grossos do sudoeste do batólito granítico São Vicente, entre os morros da Bocaina, no pantanal de Mimoso, município de Santo Antônio de Laverger e foram denominadas de as "Fontes Thermaes da Bahia do Frade".

Em 1913, foram publicados no livro "Twentieth Century Impressions of Brazil" alguns dados sobre a fonte Termal do Frade (Corrêa Netto, 1920). As águas termais identificadas como "Fontes Thermaes de S. Lourenço" foram estudadas inicialmente em 1907 pela Comissão Rondon.

Em 1917, o Coronel Rondon conseguiu reconhecer na região as seguintes fontes: Fontes Thermaes do S. Lourenço; Fontes Thermaes do
Bahia do Frade; Fontes Thermaes de Palmeiras (Corrêa Netto, 1920).

Somente em 1920, na publicação $\mathrm{n}^{\circ} 61$ "Aguas Thermaes de Mato-Grosso", as fontes da fazenda Palmeiras foram referenciadas em número de 11 fontes termais, que passaram a ser conhecidas como "Fontes Termais de Águas Quentes (Palmeiras), sendo as três principais designadas de Paulista, do Feio e Dom Aquino (Corrêa Netto, 1920).

Deve-se a Correa Neto (1946) a publicação com a integração final dos dados até então obtidos de artigo denominado "Águas Termais de Mato Grosso, com estudo in loco das fontes de Palmeiras e Bahia do Frade".

O Projeto Águas Quentes (CPRM, 1973) constitui o primeiro trabalho de cunho geológico no balneário de São Vicente, município de Santo Antonio do Leverger. A partir de 1980, novas pesquisas foram realizadas nas fontes termais de Juscimeira (FEMA, 1997; EMBRATUR, 2008). Recentemente, trabalhos de cunho geológicos e hídricos em referência a estas áreas devem-se a Abreu Filho \& Thomé Filho (2000), Lacerda Filho et al. (2004), Migliorini (1999), Migliorini et al. (2006), Godoy (2014) e Godoy et al. (2016).

\section{MÉTODO DE ESTUDO}

A elaboração das informações de apoio ao Geoturismo teve como enfoque aspectos relacionados ao tema e deverão conter informações abrangentes e atualizadas sobre a região, quanto aos aspectos geológicos, geomorfológicos, hidrogeológicos e ocupacionais da região relacionadas aos atrativos turísticos.

As fases da pesquisa envolveram grande número de informações:

- Identificação, resgate e compilação das informações existentes voltadas para destacar as particularidades da geologia, hidrogeologia, geomorfologia e características turísticas da área;

- Preparação de bases cartográficas para elaboração de mapas temáticos (topográficos, geológicos, hidrológicos, etc.);
- O levantamento de todos os dados hidrológicos dos municípios e o cadastramento dos poços regularizados foram obtidos a partir dos trabalhos de campo, em nível municipal, estadual e particulares, além de dados obtidos a partir do banco de dados SIAGAS-CPRM da Companhia de Pesquisa de Recursos Minerais (SIAGAS, 2013);

- Os trabalhos em campo foram feitos no reconhecimento e descrição sempre georreferenciadas dos afloramentos geológicos, dos tipos litológicos presentes, solos, águas e da geomorfologia local, baseada na descrição da paisagem e na caracterização de áreas turísticas, como: cachoeiras, rios, cavernas, serras e morros, além da visitação às secretarias de turismo, hotéis e termas;

- Para a avaliação dos impactos ambientais, 
adotou-se o método VIM - Visitor Impact Management (Graefe et al., 1990), que representa uma metodologia de gerenciamento projetada para a identificação e controle do impacto previsto de turistas em um dado atrativo. O método VIM já foi utilizado nos parques nacionais do Iguaçu (PR) e Itatiaia (RJ/MG/SP), no Parque Estadual Intervales (SP) (Magro, 1999; 2001), no Município de Altinópolis (SP) (Sardinha et al., 2007), no município de Rifaina (Zanfelice et al., 2009) e, até mesmo em propriedades particulares (Freixêdas-Vieira et al., 2000).

As etapas do método VIM (Graefe et al., 1990) desenvolvida neste trabalho, encontramse resumidas em oito etapas segundo Sardinha et al. (2007) e, serão aplicadas e apresentadas da seguinte maneira: 1. Pré-avaliação e revisão de informações; 2. Revisão dos objetivos de manejo; 3. Seleção dos indicadores de impacto; 4. Seleção de pesos para os indicadores de impacto; 5. Avaliação de condições existentes; 6. Identificação das causas prováveis dos impactos; 7. Identificação das estratégias de manejo e 8. Monitoramento. Tais etapas foram aplicadas em todos os atrativos turísticos listados: rafting (A); cachoeira da Fumaça (B), cachoeira da Mulata (C), cachoeira do Canal (D), cachoeira Saia Branca (E), cachoeira do Bambu (F), gruta de Inscrições Rupestre (G), cachoeira do Prata $(\mathrm{H})$; cachoeira do Bispo (I).

- Para avaliação e quantificação dos impactos provenientes das atividades turísticas, relacionadas aos atrativos turísticos naturais também foi utilizado o modelo PER (PressãoEstado-Resposta) proposto pela OECD (1994), aplicado aos resultados obtidos das etapas seis e sete da aplicação do Método Vim, que obtiveram alto a preocupante impacto ambiental para as atividades analisadas, possibilitando assim, avaliar as causas e estabelecer as estratégias de manejo aos atrativos naturais.

As cinco etapas iniciais propiciam a identificação do problema e suas condições e se baseiam no levantamento de todas as informações técnicas pertinentes à área estudada e seus atrativos, incluindo os objetivos do uso atual desses atrativos.

Tabela 1. Modelo de ficha de campo com indicadores biofísicos de impactos ambientais e seus respectivos pesos e valores atribuídos aos indicadores biofísicos avaliados em cada atrativo (Sardinha et al., 2007).

\begin{tabular}{|c|c|c|c|}
\hline Indicadores Biofísicos & Peso & Indicadores Biofísicos & Peso \\
\hline \multicolumn{2}{|c|}{ Cobertura vegetal } & \multicolumn{2}{|l|}{ Erosão } \\
\hline Sem vegetação & 0 & Boçoroca & 0 \\
\hline Vegetação rasteira & 1 & Ravina & 1 \\
\hline Vegetação arbustiva & 2 & Sulco & 2 \\
\hline Vegetação arbórea & 3 & Sem erosão & 3 \\
\hline \multicolumn{2}{|l|}{ Fauna no entorno } & \multicolumn{2}{|c|}{ Risco a saúde } \\
\hline Ausência & 0 & Acidente fatal & 0 \\
\hline Pouca presença & 1 & Acidente traumático & 1 \\
\hline Moderada presença & 2 & Acidente leve & 2 \\
\hline Muita presença & 3 & Sem risco associado & 3 \\
\hline \multicolumn{2}{|l|}{ Lixo no entorno } & \multicolumn{2}{|l|}{ Impacto Sonoro } \\
\hline Muito lixo & 0 & Grande & 0 \\
\hline Pouco lixo & 1 & Média & 1 \\
\hline Lixo em latões & 2 & Pequena & 2 \\
\hline Sem lixo & 3 & Ausente & 3 \\
\hline \multicolumn{2}{|l|}{ Saneamento } & \multicolumn{2}{|c|}{ Danos no atrativo } \\
\hline Esgoto & 0 & Vandalismo & 0 \\
\hline Fossa & 1 & Danos no entorno & 1 \\
\hline Dejetos & 2 & Inscrições & 2 \\
\hline Ausente & 3 & Sem danos & 3 \\
\hline \multicolumn{4}{|c|}{ TOTAL DE PONTOS: } \\
\hline \multicolumn{2}{|l|}{ Intervalo de Valores } & \multicolumn{2}{|c|}{ Classificação dos Impactos } \\
\hline \multicolumn{2}{|l|}{$24-19$} & \multicolumn{2}{|l|}{ Pouco Impacto } \\
\hline \multicolumn{2}{|l|}{$18-13$} & \multicolumn{2}{|l|}{ Impacto Moderado } \\
\hline \multicolumn{2}{|l|}{$12-7$} & \multicolumn{2}{|l|}{ Impacto Alto } \\
\hline \multicolumn{2}{|l|}{$6-0$} & \multicolumn{2}{|l|}{ Impacto Preocupante } \\
\hline
\end{tabular}


Destas cinco etapas iniciais, na terceira etapa, procedeu-se à seleção de indicadores buscando a identificação dos problemas relevantes, assim como o levantamento de fatores que refletiam os impactos no ambiente de estudo e, na quarta etapa referiu-se à definição de pesos (padrões) para cada impacto no entorno dos atrativos turísticos. Foi utilizado um questionário de campo e os valores atribuídos aos indicadores biofísicos avaliados em cada atrativo (Tabela 1).

A etapa seis tem como objetivo a determinação das prováveis causas dos problemas diagnosticados e, as etapas sete e oito trataram da seleção de possíveis estratégias de controle e/ou redução dos impactos (Freixêdas-Vieira et al., 2000).

\section{CARACTERIZAÇÃO DA ÁREA}

As áreas dos municípios estudadas situam-se na porção oeste do flanco noroeste da Bacia do Paraná, ocupando a porção centro-meridional de Mato Grosso, na borda sudeste do Cráton Amazônico. A região localiza-se na unidade geomorfológica denominada Depressão do Alto Paraguai, constituída na área pelas subunidades do Planalto dos Guimarães, Planalto dos Alcantilados, Depressões Rondonópolis e Planície Pantanal (Figura 2).

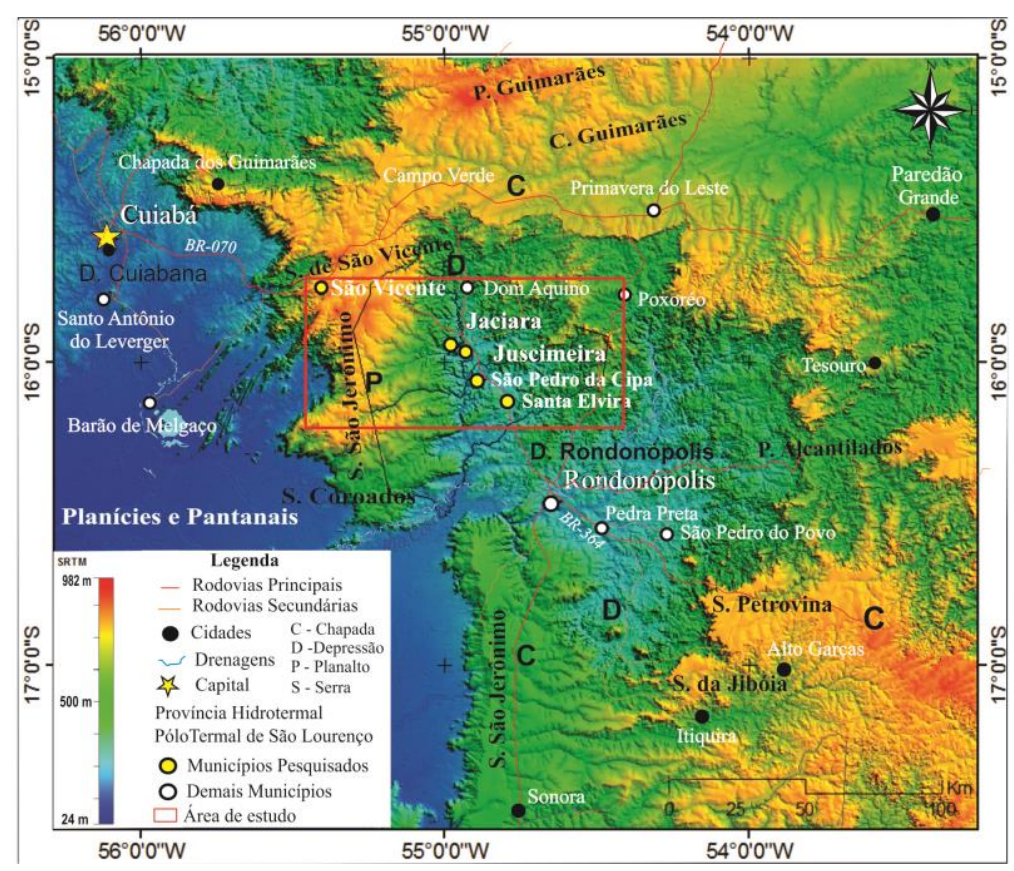

Figura 2. Imagem do relevo da região coletados pelo sensor Shuttle Radar Topography Mission - SRTM.

A região do Polo Turístico das Águas de São Lourenço é caracterizada por duas áreas turísticas principais. São áreas próximas, mas distintas quanto aos aspectos litológicos, a região do vale do rio São Lourenço utilizados por inúmeras termas e pelo turismo originado das atividades ligadas as águas superficiais e a região da serra de São Vicente utilizada pela Terma das Águas Quentes, a mais antiga do estado do Mato Grosso.

As áreas termais da bacia do vale do rio São Lourenço são constituídas na parte externa pelas unidades litológicas mais elevadas do Planalto dos Guimarães. Esta subunidade é caracterizada na sua porção leste por feição de relevo cuestiforme, que constituem as Serra dos Coroados, São Jerônimo e São Vicente, em que predominam as sequências superiores das litologias sedimentares da Bacia do Paraná (formações Aquidauana, Botucatu e Cachoeirinha) e granitos variedades do Batólito São Vicente.

O Planalto dos Alcantilados é caracterizado por uma região de relevo acidentado que corresponde à transição entre as regiões de planalto e depressão, e é composto principalmente pelas formações Ponta Grossa e Aquidauana. 
A parte central principal da depressão, a Depressão de Rondonópolis é constituída pelo vale do rio São Lourenço, em que se expõem as rochas sedimentares inferiores da Bacia do Paraná (formações Furnas, Ponta Grossa).

As Planícies e Pantanais Matogrossense constituem as regiões mais baixas, a oeste das Serra dos Coroados, São Jerônimo e São Vicente, nas quais aflora os sedimentos recentes da Bacia do Pantanal. As unidades geológicas podem ser observadas no mapa geológico de Lacerda et al. (2004) da figura 3.

O Planalto dos Guimarães situa-se entre as cotas mais elevadas e caracteriza-se pela suavidade do modelado, predominando as amplas formas de topos tabulares e bordas marcadas por escarpas erosivas. As serras dos Coroados ou São Jerônimo definem uma feição elevada plana e em ativa fase de dissecação, onde os chapadões constituem os representantes remanescentes de sedimentos da Formação Cachoeirinha e sedimentos recentes indiferenciados. Esta região define na área de maior importância para manutenção, captação e infiltração das águas dos aquíferos desta região turística.

A subunidade do Planalto dos Guimarães é composta, na borda oeste das serras dos Coroados, São Jerônimo e São Vicente, por um fronte de cuesta fortemente dissecado a exposição que expõem as rochas sedimentares da Bacia do Paraná (formações Ivaí, Furnas e Ponta Grossa), além das rochas epimetamórficas do Grupo Cuiabá da Faixa de Dobramento Paraguai, os granitos do Batólito São Vicente e os sedimentos da Bacia do Pantanal.

Nestes contrafortes erosivos das serras, ocupando uma faixa estreita e descontínua, expõem-se as unidades geológicas neoproterozóicas mais antigas da área, as rochas da Faixa de Dobramento Paraguai. São rochas epimetamórficas do Grupo Cuiabá, constituídas principalmente por filitos, metarritmitos, xistos e, secundariamente, metarenitos, metarcóseos metaconglomerados.

A norte-nordeste da área, na serra de São
Vicente, intrudidas em rochas do Grupo Cuiabá, encontram-se rochas graníticas do Batólito Granítico Neoproterozoico São Vicente, com uma área aflorante de $437 \mathrm{~km}^{2}$. Estas rochas são constituídas por biotita granitos e moscovita-biotita granitos, isotrópicos, inequigranulares e porfiríticos, localmente cataclástico, intrudido por inúmeros diques e veios aplíticos e/ou pegmatóides. Estes dois conjuntos de rochas delimitam a oeste com uma área plana e arrasada de exposição dos sedimentos recentes da Bacia do Pantanal, a Planície Matogrossense.

A oeste do batólito, no município de Santo Antônio de Leverger, associado ao contato do Granito São Vicente e sedimentos da Bacia do Pantanal, ocorrem as nascentes das águas denominadas as "Fontes Thermaes da Bahia do Frade". Na parte central do Granito São Vicente, os granitos são cortados por grandes diques graníticos microporfiríticos, aos quais estão associadas as águas denominadas de "Fontes Termais de Palmeiras", que acompanham e ajudam a compor as águas no córrego das Águas Quentes, constituindo nas termas mais antiga e conhecida do estado do Mato Grosso.

A subunidade do Planalto dos Acantilados é caracterizada por uma superfície topograficamente ondulada resultante da atuação de intensos processos erosivo. Esta unidade é formada por um conjunto de relevo muito dissecado, elaborado em litologias sedimentares das formações Ponta Grossa, Aquidauana e Botucatu.

A área é formada por relevos recortados por escarpas abruptas alcantiladas e relevos residuais de formas estruturais tabulares com vertentes abruptas, que são sustentadas pelas rochas pertencentes à Formação Ponta Grossa, e são observados no alto da bacia hidrográfica do rio São Lourenço. A área foi fortemente influenciada pela tectônica que originou patamares estruturais posicionados em diferentes níveis altimétricos, pelas escarpas associadas às linhas de falha, pela sequência de formações geológicas e pela atuação dos processos erosivos. 


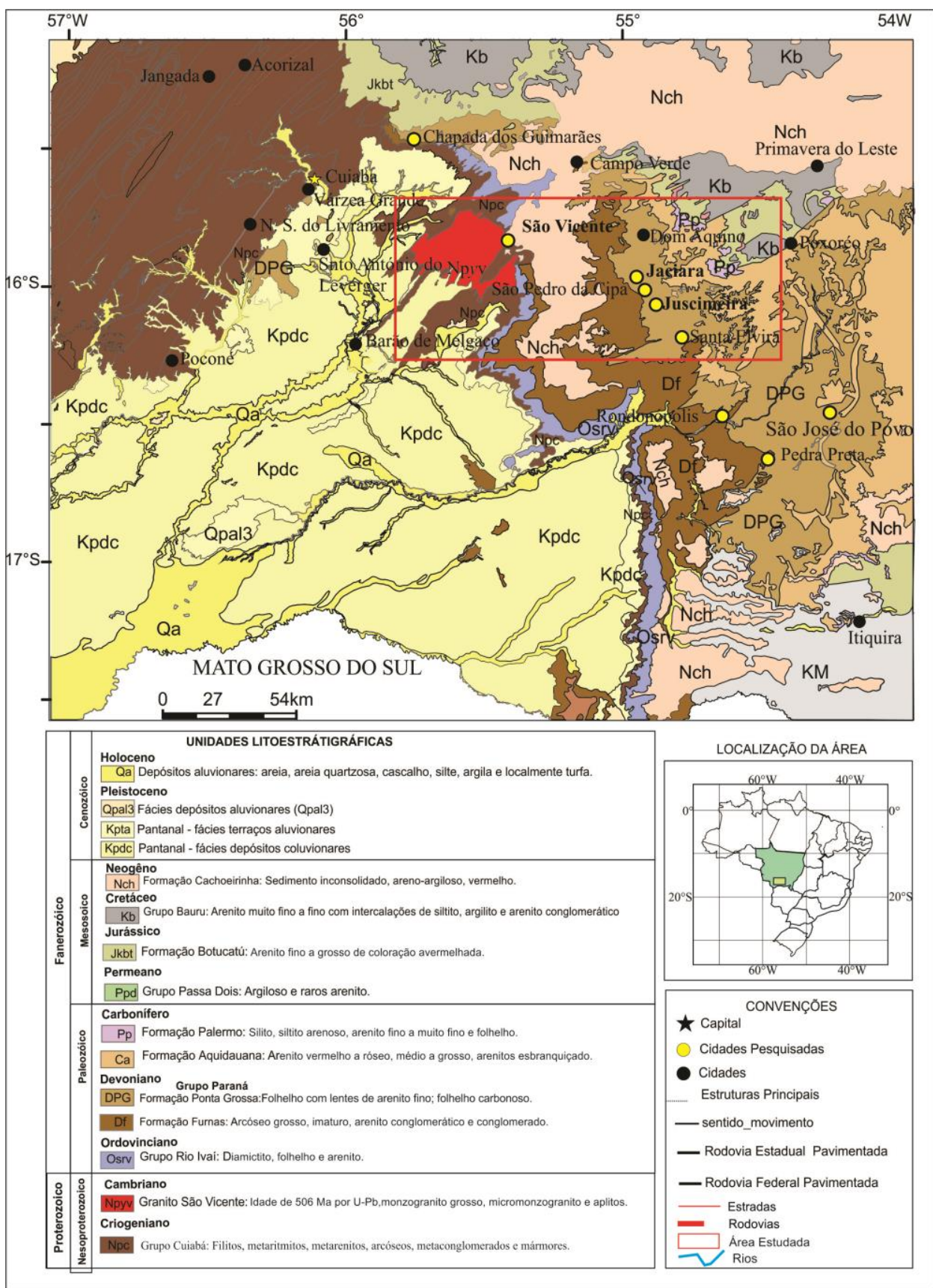

Figura 3. Mapa geológico regional da região do Polo Turístico de São Lourenço e seu entorno.

Fonte: Mod. de Lacerda et al. (2004).

A região central é marcada pela unidade geomorfológica da Depressão de Rondonópolis, que corresponde a uma área situada abaixo da cota de $300 \mathrm{~m}$, caracterizada pela bacia do vale do rio São Lourenço. Constitui um sub compartimento elaborado nos arenitos da Formação Aquidauana, associado com as áreas de maior aprofundamento da drenagem, que entalham os arenitos, folhelhos, argilitos e conglomerados das rochas sedimentares devonianas da Bacia do Paraná (formações Furnas e Ponta Grossa), além de coberturas cenozóicas e sedimentos recentes.

O Aquífero Furnas corresponde na área a unidade basal da Bacia Sedimentar do Paraná e possui excelentes condições de armazenamento e circulação das águas subterrâneas por apresentar porosidade, fraturamento e uma grande extensão. Os sedimentos da Formação Ponta Grossa não possuem boas condições de armazenamento e circulação das águas subterrâneas.

Os sedimentos Furnas apresentam boas vazões como um aquífero do tipo livre e em condições de aquífero do tipo confinado de extensão regional e recobertos pelas rochas de Formação Ponta Grossa, constituem uma unidade aquífera de grande expressão e altas 
vazões, além de artesianismo e termalismo, pois mantém toda sua espessura preservada, tornando-a o principal reservatório de água subterrânea da região.

A oeste do município, margeando o rio São Lourenço, encontram-se escarpas íngremes do arenito Furnas e Ponta Grossa, resultantes de tectonismo de gravidade associado a processos erosivos e, constituem a depressão do rio, com as áreas com as unidades sedimentares mais profundas expostas. O conjunto de rochas sedimentares que afloram na área apresenta-se sub horizontalizado, localmente basculado pela ação de falhamentos gravitacionais. $\mathrm{Na}$ área das Serra dos Coroados e São Jerônimo dominam nas partes mais elevadas os sedimentos Aquidauana e, sobreposto, as rochas da Formação Cachoeirinha.

A região leste do município, posicionada entre o planalto e a depressão, ocorre uma subunidade conhecida por Planalto dos Alcantilados, elaborado em litologias sedimentares das formações Ponta Grossa e Aquidauana.

O grande potencial das Águas Quentes do Balneário de São Vicente, para fins turísticos, constitui um importante segmento na economia do estado e é formado por 11 fontes termais, das quais 3 são as fontes principais e as demais com volume subordinados, encontrando-se submersas no córrego Águas Quentes.

O termalismo associado ao batólito granítico da Serra de São Vicente, a água das fontes provém da infiltração de águas de chuvas superficiais, capitada em um grande anfiteatro erosivo na parte central do corpo ígneo a partir das rochas sedimentares sotopostas e, pelo espesso solo preservado da reserva florestal de Águas Quentes. O forte fraturamento no corpo ígneo é condicionante para percolação e infiltração, já que os granitos são quase rochas impermeáveis.

A manutenção de alta vazão das fontes termais deve-se a uma área de recarga abrangente, de rochas fortemente fraturadas, de perda de calor deve ser relativamente baixa e de raras ocorrências de fontes frias na área. Estes fatores propiciam a infiltração profunda das águas meteóricas e a pouca mistura de águas de profundidades rasas.

O termalismo de São Lourenço associado ao aquífero dos arenitos da Formação Furnas, apresenta-se com altas vazões, além de artesianismo e termalismo e, tem como causa o grau geotérmico da região com um alto fluxo térmico e a associação às falhas e fraturas abertas em profundidade, representadas por sistema de falhamentos de abrangência regional que interceptam nesta região de direção N-S e NE-SW.

As águas termais são águas de chuvas que penetraram no solo, infiltra $\mathrm{e}$ abastece $\mathrm{o}$ aquífero termal e, descem em profundidade a partir de grandes fraturamentos. A partir do contato com as rochas aquecidas pelo gradiente geotérmico da área, são aquecidas e mineralizadas e, pela variação térmica da água, circulam em direção a superfície. As águas minerais superficiais estão geneticamente condicionadas ao aquífero Ponta Grossa e Furnas e afloram principalmente sob a forma de surgência, preferencialmente na zona de contato da Formação Furnas com a Formação Ponta Grossa.

A principal área de recarga do aquífero ocorre principalmente pelas unidades superiores à formação Furnas na Serra de São Jerônimo, que são de extrema importância para as águas termais, pois é naquele setor que se processa o maior volume de recarga das águas.

\section{POTENCIAL TURÍSTICO E AVALIAÇÃO DOS IMPACTOS}

A estância hidromineral do Polo Turístico de São Lourenço - MT encontra-se associada aos recursos hídricos da região, a partir da utilização das águas minerais, termais e superficiais e, os municípios sobrevivem economicamente da utilização destes recursos para a atividade turística. Estes recursos hídricos são analisados e preservados pelo órgão estadual Fundação Estadual do Meio
Ambiente - FEMA/MT.

As águas minerais e termais estão sendo utilizadas para exploração turística através de balneários e hotéis (Figura 4). Mais informações sobre a região encontram-se em Godoy (2014), Godoy et al. (2016) e no Portal de Mato Grosso (http://www.matogrossoeseusmunicipios.com.b $\mathrm{r} /)$. 


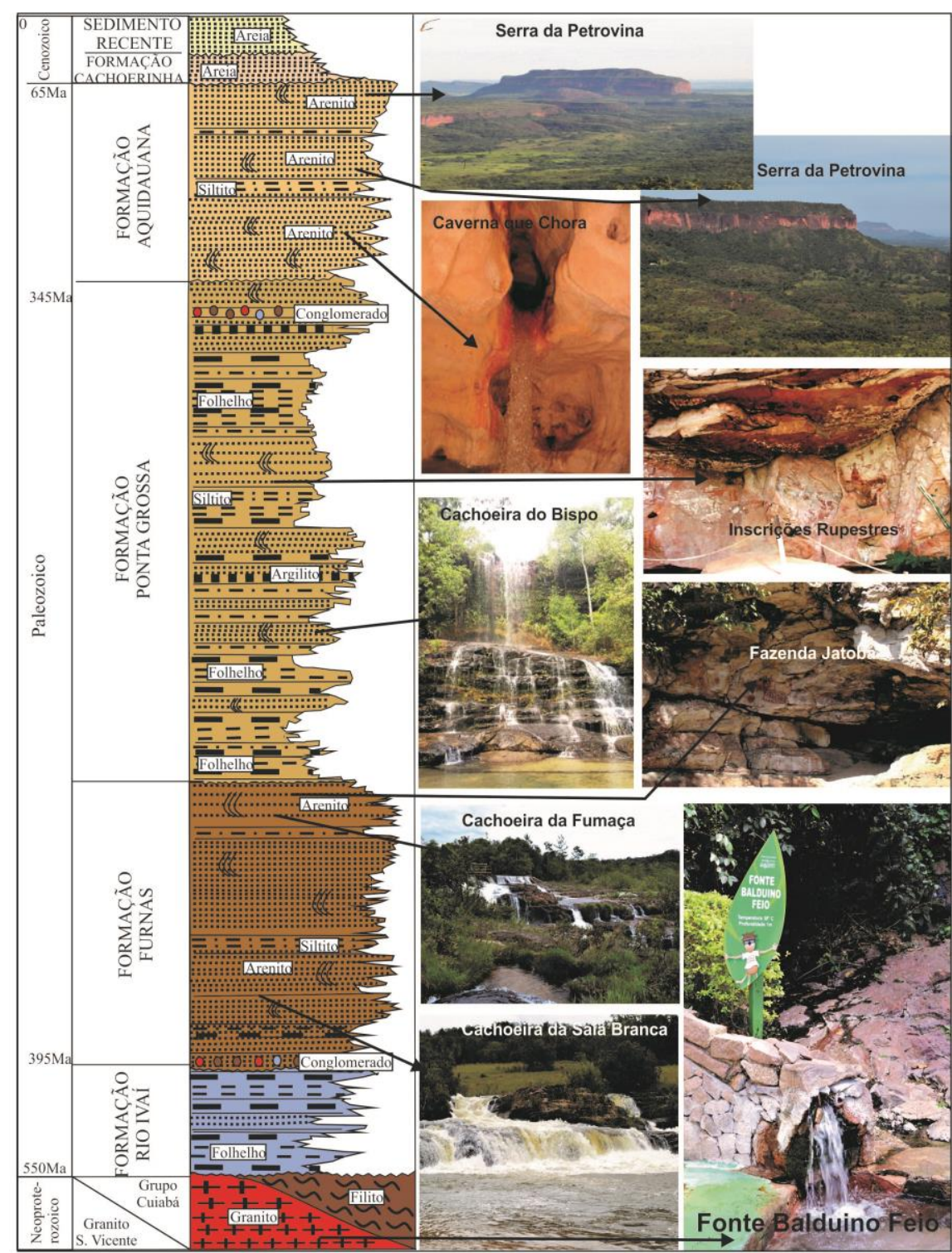

Figura 4. Principais balneários e hotéis na região do Polo de São Lourenço-MT

Legenda: A) balneário Tropical; B) balneário Sesc; C) termas Alphaville; D) termas Cachoeira da Fumaça; E) termas Mariah; F) termas Águas Quentes.

Legenda: A) balneário Tropical; B) balneário Sesc; C) termas Alphaville; D) termas Cachoeira da Fumaça; E) termas Mariah; F) termas Águas Quentes.

A figura 5 apresenta o empilhamento litológico, encontram-se enumerados os esquemático dos litotipos rochosos simplificado principais atrativos turísticos estudados do polo da região e, associada ao posicionamento turístico.

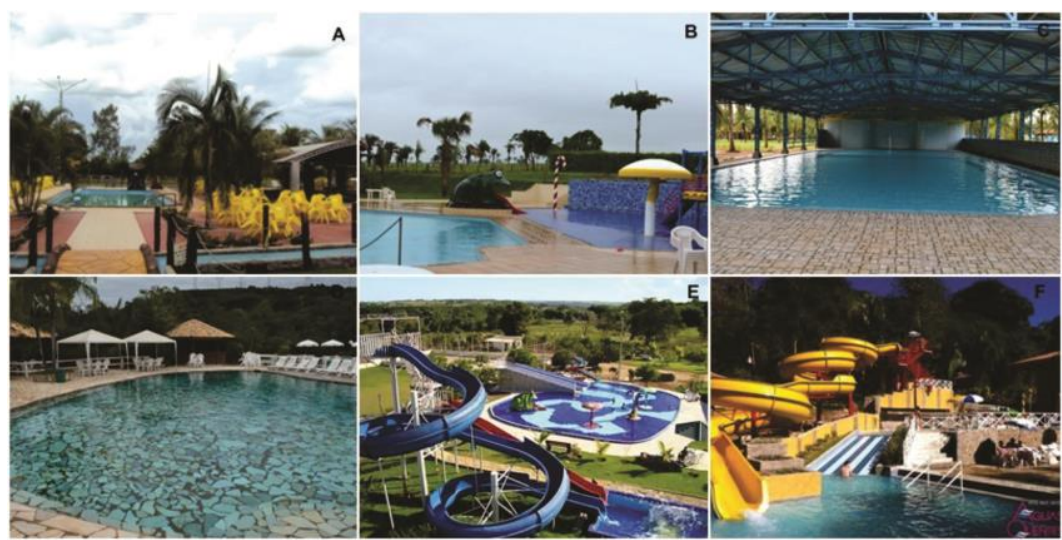

Figura 5. Empilhamento esquemático dos litotipos rochosos simplificado da área de estudo e associada ao posicionamento litológico, encontram-se enumeradas as principais ocorrências de atrativos turísticos estudados. 
Os recursos hídricos superficiais resultam em inúmeras cachoeiras e corredeiras, com imensas possibilidades para a prática do geoturismo e ecoturismo e, que estão sendo mais abordadas neste trabalho. As avaliações de classificação dos impactos nos atrativos dos municípios encontram-se sintetizadas na tabela 2; na figura 6 vislumbra-se as fotos dos principais atrativos analisados.

Tabela 2. Classificação final com os indicadores biofísicos de impactos ambientais com seus respectivos pesos e valores atribuídos aos indicadores biofísicos avaliados em cada atrativo.

\begin{tabular}{|c|c|c|c|c|c|c|c|c|c|c|}
\hline \multicolumn{2}{|l|}{ Atrativos } & $\mathbf{A}$ & $\mathbf{B}$ & $\mathbf{C}$ & D & $\mathbf{E}$ & $\mathbf{F}$ & $\mathbf{G}$ & $\mathbf{H}$ & I \\
\hline Indicadores Biofísicos & Peso & & & & & & & & & \\
\hline \multicolumn{11}{|c|}{ Cobertura Vegetal } \\
\hline Sem vegetação & $\mathbf{0}$ & & & & & & & & & \\
\hline Vegetação rasteira & 1 & & & & & & & & & \\
\hline Vegetação arbustiva & 2 & & & & & $\mathbf{X}$ & & $\mathbf{X}$ & $\mathbf{X}$ & \\
\hline Vegetação arbórea & 3 & $\mathbf{X}$ & $\mathbf{X}$ & $\mathbf{X}$ & $\mathbf{X}$ & & $\mathbf{X}$ & & & $\underline{\mathbf{X}}$ \\
\hline \multicolumn{11}{|c|}{ Fauna no entorno } \\
\hline Ausência & $\mathbf{0}$ & & & & & & & & $\mathbf{X}$ & \\
\hline Pouca presença & 1 & & & $\mathbf{X}$ & & $\mathbf{X}$ & & $\mathbf{X}$ & & \\
\hline Moderada presença & 2 & $\mathbf{X}$ & $\mathbf{X}$ & & $\mathbf{X}$ & & $\mathbf{X}$ & & & $\mathbf{X}$ \\
\hline Muita presença & 3 & & & & & & & & & \\
\hline \multicolumn{11}{|l|}{ Lixo no entorno } \\
\hline Muito lixo & $\mathbf{0}$ & & & & & & & & $\mathbf{X}$ & \\
\hline Pouco lixo & 1 & & $\mathbf{X}$ & & & $\mathbf{X}$ & & $\mathbf{X}$ & & $\mathbf{X}$ \\
\hline Lixo em latões & 2 & $\mathbf{X}$ & & $\mathbf{X}$ & $\mathbf{X}$ & & & & & \\
\hline Sem lixo & 3 & & & & & & $\mathbf{X}$ & & & \\
\hline \multicolumn{11}{|l|}{ Saneamento } \\
\hline Esgoto & $\mathbf{0}$ & & & & & & & & & \\
\hline Fossa & 1 & & & & & & & & & \\
\hline Dejetos & 2 & & & & & & & $\mathbf{X}$ & $\mathbf{X}$ & \\
\hline Ausente & 3 & $\mathbf{X}$ & $\mathbf{X}$ & $\mathbf{X}$ & $\mathbf{X}$ & $\mathbf{X}$ & $\mathbf{X}$ & & & $\mathbf{X}$ \\
\hline \multicolumn{11}{|l|}{ Erosão } \\
\hline Boçoroca & $\mathbf{0}$ & & & & & & & & & \\
\hline Ravina & 1 & & & & & & & & & \\
\hline Sulco & 2 & $\mathbf{X}$ & $\mathbf{X}$ & $\mathbf{X}$ & $\mathbf{X}$ & $\mathbf{X}$ & & & & $\mathbf{X}$ \\
\hline Sem erosão & 3 & & & & & & $\mathbf{X}$ & $\mathbf{X}$ & $\mathbf{X}$ & \\
\hline \multicolumn{11}{|l|}{ Risco a saúde } \\
\hline Acidente fatal & $\mathbf{0}$ & & & & & & & & & \\
\hline Acidente traumático & 1 & $\mathbf{X}$ & $\mathbf{X}$ & $\mathbf{X}$ & $\mathbf{X}$ & & $\mathbf{X}$ & & & $\mathbf{X}$ \\
\hline Acidente leve & 2 & & & & & $\mathbf{X}$ & & & $\mathbf{X}$ & \\
\hline Sem risco associado & 3 & & & & & & & $\mathbf{X}$ & & \\
\hline \multicolumn{11}{|l|}{ Impacto sonoro } \\
\hline Grande & $\mathbf{0}$ & & & & & & & & $\mathbf{X}$ & \\
\hline Média & 1 & & & & & & & & & \\
\hline Pequena & 2 & & $\mathbf{X}$ & & & & & & & \\
\hline Ausente & 3 & $\mathbf{X}$ & & $\mathbf{X}$ & $\mathbf{X}$ & $\mathbf{X}$ & $\mathbf{X}$ & $\mathbf{X}$ & & $\mathbf{X}$ \\
\hline \multicolumn{11}{|l|}{ Danos no atrativo } \\
\hline Vandalismo & $\mathbf{0}$ & & & & & & & & & \\
\hline Danos no entorno & 1 & & & & & & & $\mathbf{X}$ & & \\
\hline Inscrições & 2 & & & & & & & & $\mathbf{X}$ & \\
\hline Sem danos & 3 & $\mathbf{X}$ & $\mathbf{X}$ & $\mathbf{X}$ & $\mathbf{X}$ & $\mathbf{X}$ & $\mathbf{X}$ & & & $\mathbf{x}$ \\
\hline \multicolumn{2}{|c|}{$\begin{array}{l}\text { TOTAL DE PONTOS } \\
\text { TOL }\end{array}$} & 19 & 17 & 18 & 19 & 17 & 21 & 16 & 11 & 18 \\
\hline
\end{tabular}



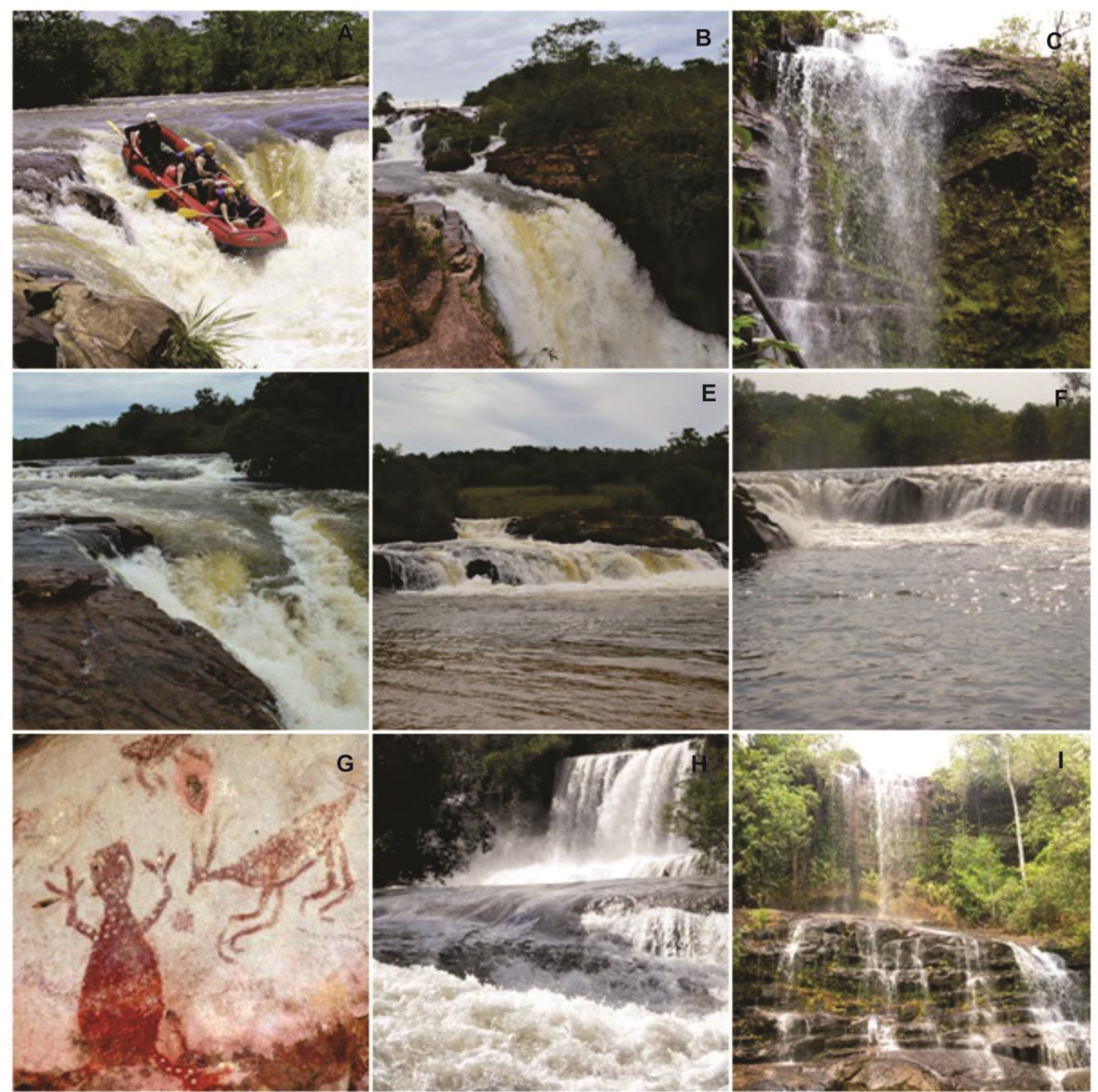

Figura 6. Fotografia dos principais atrativos turísticos da região do Polo Turístico de São Lourenço.

Legenda. A) rafting no rio Tenente Amaral; B) cachoeira da Fumaça; C) cachoeira da Mulata; D) cachoeira Canal; E) cachoeira Saia branca; F) cachoeira do Bambu; G) gruta Vale das Perdidas; H) cachoeira do Prata; I) cachoeira do Bispo.

A tabela 3 apresenta um sumário com os valores de impactos ambientais. Para a maioria dos atrativos turísticos há mínimo ou moderado impacto ambiental, sendo os pontos $\mathrm{A}, \mathrm{D}, \mathrm{F}$, impacto mínimo e nos pontos B, C, E, G, I com impacto moderado. Já a cachoeira do Prata $(\mathrm{H})$ apresentou impacto ambiental alto a preocupante.

Assim, pelo uso do método VIM, apenas esses pontos foram identificados, bem como as causas prováveis desses impactos (fase 6) e estratégias de manejo (fase 7). Após a realização dessas etapas, esses pontos deverão ser monitorados para avaliação de dados ambientais para orientação da melhor maneira de manejo.

Utilizando o modelo de PER - PressãoEstado-Resposta (OECD, 1994), foi possível identificar algumas estratégias de manejos para os atrativos naturais que possuem alto a preocupante impacto ambiental, ou seja, a Cachoeira do Prata. Entre os impactos, destacam-se o vandalismo no entorno e o impacto sonoro, além da perda da biodiversidade e da cobertura vegetal. 
Tabela 3. Classificação final dos impactos ambientais.

\begin{tabular}{|c|c|c|c|c|}
\hline \multirow[b]{2}{*}{ ATRATIVO TURÍSTICO } & \multicolumn{4}{|c|}{ TIPOS DE IMPACTO } \\
\hline & 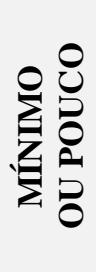 & $\begin{array}{l}0 \\
2 \\
\frac{1}{x} \\
\frac{1}{2} \\
\stackrel{0}{\Sigma}\end{array}$ & 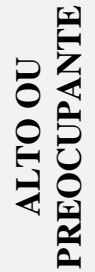 & \begin{tabular}{l}
0 \\
\multirow{2}{*}{} \\
0 \\
2 \\
2 \\
2
\end{tabular} \\
\hline \multicolumn{5}{|l|}{ JACIARA } \\
\hline Rafting (A) & $\mathbf{x}$ & & & \\
\hline Cachoeira da Fumaça (B) & & $\mathbf{x}$ & & \\
\hline Cachoeira da Mulata (C) & & $\mathbf{x}$ & & \\
\hline Cachoeira do Canal (D) & $\mathbf{x}$ & & & \\
\hline Cachoeira Saia Branca $(\mathrm{E})$ & & $\mathbf{x}$ & & \\
\hline Cachoeira do Bambu (F) & $\mathbf{x}$ & & & \\
\hline Gruta - Vale das Perdidas (G) & & $\mathbf{x}$ & & \\
\hline \multicolumn{5}{|l|}{$\begin{array}{ll}\text { JUSCIMEIRA } \\
\end{array}$} \\
\hline Cachoeira do Prata $(\mathrm{H})$ & & & $\mathbf{x}$ & \\
\hline Cachoeira do Bispo (I) & & $\mathbf{x}$ & & \\
\hline
\end{tabular}

A conservação e o uso sustentável dos recursos naturais são essenciais para um meio ambiente sadio em longo prazo. A concentração de visitantes no tempo e no espaço pode impor um sacrifício muito pesado aos recursos naturais como a água. Sistemas de manejo turístico devem se esforçar para distribuir, da melhor forma, os fluxos turísticos ao longo do ano e, a renda obtida deve apoiar tecnologias e estratégias de uso sustentáveis.

Todos esses impactos podem ser corrigidos por uma administração pública mais eficiente em relação à gestão ambiental municipal. Educação, conscientização e capacitação compõem a base do turismo responsável. Todos os integrantes do setor devem ser alertados sobre seus impactos positivos e negativos e encorajados a serem responsáveis e apoiar a conservação por meio de suas atividades:

Reduzindo a poluição, os danos ambientais também serão menores, melhorando a experiência do turismo, reduzindo os custos operacionais e de recuperação do ambiente. Algumas medidas de manejo poderiam ser adotadas para reduzir esses impactos nas áreas rurais ou áreas urbanas, tais como: cumprimento legal e conservação de APPs; recuperação de áreas degradadas; controle e planejamento da expansão urbana; estrutura adequada de prestação de serviços e sinalização; fiscalização de atrativos turísticos naturais para se evitar riscos à saúde, a perturbação dos ecossistemas e danos no entorno; coleta e disposição adequada dos resíduos sólidos; sistema de tratamento de efluentes.

\section{RECOMENDAÇÕES}

A partir dos estudos realizados foram propostas as seguintes medidas de preservação das águas termais e dos pontos turísticos da região:

- Preservação ambiental da Serra de São Vicente com o mínimo de uso e ocupação, pois as fontes hídricas desta área dependem basicamente da recarga das águas das chuvas que é preservada no pequeno solo granítico da reserva florestal de Águas Quentes, já que os granitos são quase impermeáveis;

- Estudos de detalhe das rochas das áreas para a definição de regimes regionais e locais de fluxo hidrogeológico;

- Desenvolvimento de estudos geofísicos para determinação das espessuras dos solos para melhores conhecimentos dos mecanismos de recarga; 
- Restrição de autorizações de novas perfurações de poços tubulares profundos e a limitação do bombeamento dos poços existentes indiscriminadamente, principalmente para uso em atividades na agricultura;

- Controle e conservação das Áreas de Proteção Permanente e recuperação das áreas degradadas;

- Estruturação dos pontos turísticos, fiscalização dos atrativos naturais e coleta e disposição adequada dos resíduos sólidos;

- Melhorarias da colaboração entre os órgãos governamentais e as operadoras de turismo;

- Capacitação de mão de obra qualificada e programas de educação ambiental para turistas e população local. Esses programas de educação ambiental podem despertar nas pessoas a conscientização dos valores dos ecossistemas encontrados, relacionando os recursos naturais com o cotidiano dos habitantes.

Obrigatoriamente, todas estas propostas têm de ser levadas em consideração pelos administradores e sociedade em geral vindo ao encontro da necessidade de criar políticas de gestão sustentável das águas do Aquífero Termal, considerando que o citado aquífero, apesar de caráter renovável, é limitado, vulnerável a resfriamento à ação antrópica e, ainda não teve seu potencial devidamente avaliado.

Os municípios sobrevivem, economicamente, da atividade turística, que depende da infiltração da água da chuva para renovação do manancial termal e, portanto, um bem que pode não ser totalmente renovável, principal produto que proporcionou $\mathrm{o}$ desenvolvimento dessa atividade.

Dessa forma, manter esse patrimônio significa contribuir com a preservação deste recurso natural tão raro e importante para o desenvolvimento socioeconômico de Jaciara e Juscimeira.

É necessário também que sejam feitos investimentos na estrutura dos atrativos turísticos, pois estes não oferecem condições básicas de conforto e segurança para o turista. Seria de extrema importância a criação de um plano de ação para o turismo da região, um plano em que fossem descritos todos os atrativos com um histórico, fotos, mapas de acesso e, que fossem previstas melhorias nesses planos com ações de investimentos para o turismo, como a qualificação de mão obra, reformas, marketing, divulgação e parcerias com empresas hoteleiras do estado, da região ou até mesmo com operadoras de turismo.

\section{DISCUSSÕES FINAIS}

O turismo do Polo Turístico de São Lourenço pode ser caracterizado pelas atividades resultantes de sua prática, permitindo assim uma melhor identificação dos seus tipos e subtipos e, possibilitando para os municípios envolvidos um melhor aproveitamento econômico, uma maior preservação do patrimônio e uma atividade turística mais duradoura.

Assim, o ecoturismo para a área, está diretamente relacionado com as condições ambientais das localidades visitadas, portanto quanto melhores condições ambientais, conservação das áreas naturais e valorização dos recursos naturais, maiores serão as chances de atrair interessados em visitá-las para fomentar o turismo e, consequentemente melhorem o bem-estar das populações locais a partir da participação efetiva dos segmentos atuantes no setor e, incentivo e estímulo na criação e melhoria de infraestrutura para a atividade de ecoturismo

O segmento do geoturismo para a região, compreende a atividade de prover subsídios que possibilitem aos turistas adquirirem conhecimento para compreender a geologia e a geomorfologia de um local além da apreciação de sua beleza cênica.

Toda região que explora atividade relacionada ao ecoturismo ou geoturismo tem impacto ambiental que é a alteração das propriedades físicas, químicas e biológicas do meio ambiente, resultante da atividade humana que afeta direta ou indiretamente a saúde, segurança, bem-estar da população, as atividades sociais e econômicas, a fauna e a flora do meio ambiente.

O desenvolvimento turístico e econômico da 
região está associado, majoritariamente, à presença do aquífero termal e/ou aos recursos hídricos e estreitamente ligado aos recursos turísticos, naturais e culturais disponíveis. Portanto o desenvolvimento turístico ocorre aliado ao desenvolvimento urbano, que intensificam os problemas gerados por questões como a impermeabilização do solo, aumento do volume de lixo, degradação ambiental, entre outros, que por sua vez, afetam direta ou indiretamente o aquífero termal.
Adotou-se a avaliação desses impactos nos atrativos naturais através do método VIM e modelo de Pressão-Estado-Resposta sendo obtidos resultados segundo os quais na maioria dos pontos há incidência mínima ou moderada de impacto ambiental. $O$ único ponto que apresentou impacto alto ou preocupante foi a cachoeira do Prata, sendo necessárias melhorias para o atrativo para redução do impacto sofrido com a exploração do turismo.

\section{REFERÊNCIAS BIBLIOGRÁFICAS}

1. ABREU FILHO, W. \& THOMÉ FILHO, J.J. PRIMAZ Programa de Integração Mineral no Município de Juscimeira. CPRM. Goiânia, 48 p., 2000.

2. CIFUENTES, M.A. Determinación de capacidad de carga turística en areas protegidas. Centro Agronómico Tropical de Investigación y Enseñanza (CATIE), Programa de Manejo Integrado de Recursos Naturales. Série técnica, Informe Técnico, n. 194, v. 28, p., 1992.

3. COLE, D.N. Minimizing conflict between recreation and nature conservation. In: Ecology of Greenways. SMITH, D.S. \& HELMUT, P.C. (eds). Minneapolis: University of Minnesotta Press. p. 105-122, 1993.

4. CONAMA - CONSELHO NACIONAL DO MEIO AMBIENTE. Resolução CONAMA $\mathbf{n}^{\circ} \mathbf{1}$, Brasília: IBAMA, 1986.

5. CONAMA - CONSELHO NACIONAL DO MEIO AMBIENTE. Resolução CONAMA no 237. Brasília: IBAMA, 1997.

6. CORRÊA netTO, O. Aguas Thermaes de MatoGrosso. Commissão Linhas Telegraphicas Estrategicas de Mato-Grosso ao Amazonas. Rio Janeiro, n.61, anexo 5, parte 2, 1920.

7. CORRÊA NETTO, O. Aguas thermaes de MatoGrosso. Commissão Linhas Telegraphicas Estrategicas de Mato-Grosso ao Amazonas. Rio Janeiro, n. 62, parte 2, 1946.

8. CPRM - COMPANHIA DE PESQUISA E RECURSOS MINERAIS. Projeto Águas Quentes (Relatório Final), 46 p., 1973.

9. EMBRATUR - Empresa Brasileira de Turismo. Cadernos e Manuais de Segmentação: marcos conceituais. Instituto Brasileiro de Turismo, Série Roteiros do Brasil. Secretaria Nacional de Políticas de Turismo. Departamento de Estruturação, Articulação e Ordenamento Turístico. Coordenação Geral de Segmentação. Conselho Nacional de Turismo. Câmara Temática de Segmentação. 55 p., 2008.

10. FEMA/MT - FUNDAÇÃO ESTADUAL DO MEIO AMBIENTE - MT. Qualidade da água dos principais rios da Bacia do Alto Paraguai: FEMA. 17p. CuiabáMT, 1997.

11. FREIXÊDAS-VIEIRA, M.V.; PASSOLD, A.J.; MAGRO, T.C. Impactos do uso público: um guia de campo para utilização do método VIM. In: II CONGRESSO BRASILEIRO DE UNIDADES DE
CONSERVAÇÃO. Campo Grande. Anais...Campo Grande: Fundação O Boticário de Proteção à Natureza, Rede Nacional Pró Unidade de Conservação, v. 2, p. 296-305, 2000.

12. GODOY, L.P. Potencial (Geoparque) do Polo Turístico Das Águas De São Lourenço. Rio Claro: 2014, 192p. (Tese de (Doutorado), Instituto de Geociências e Ciências Exatas da Universidade Estadual Paulista.

13. GODOY, L.P.; CONCEIÇÃO, F.T. da; GODOY, A.M. Aspectos Geológicos da região do Polo Turístico das Águas Termais de São Lourenço, MT. Geociências, v. 35, n. 1, p. 110-125, 2016.

14. GRAEFE, A.R.; KUSS, E.R.; VASKE. I.I. Visitor Impact Management - The planning framework. Washington (D.C.): National Parks and Conservation Association, 1990.

15. HAMMITT, W.E. \& COLE, D.N. Wildland recreation: ecology and management. John Willey \& Sons, 1998.

16. HOSE, T.A. Geotourism - Selling the Earth to Europe. In: Engineering Geology and the Environmen. MARINOS, P.G.; KOUKIS, G.C.; TSIAMBAOS, G.C.; STOURNAS, G.C. (eds). Roterdam, Netherlands: Balkema. p. 2.955-2.960, 1997.

17. HOSE, T.A. "Geoturismo" europeo. Interpretación geológica y promoción de la conservacióngeológica para turistas. In: Patrimonio geológico:conservación y gestión. BARRETINO, D; WINBLEDON, W.A.P; GALLEGO, E (eds). Instituto Tecnológico Geominero de España, Madrid. 212p, 2000.

18. JONES, A. Sustainability and community participation in rural tourism. Eastbourne (UK): University of Brighton, The Journal of the Leisure Studies Association. Leisure Studies: v. 12, n. 2, p. 147148, 1993.

19. KUSS, F.R.; GRAEFE, A.R.; VASKE, I.I. Visitor Impact Management-review of research. Washington (D.C): National Parks and Conservation Association, 1990

20. LACERDA FILHO, J.W.; ABREU FILHO, W.; VALENTE, C.R.; OLIVEIRA, C.C.; ALBUQUERQUE, M.C. Geologia e Recursos Minerais do Estado de Mato Grosso. Programa Integração, Atualização e Difusão de Dados de Geologia do Brasil. Convênio CPRM/SICME-MT, MME. 235 p., 2004. 
21. MAGRO, T.C. Impactos do uso público em uma trilha no planalto do Parque Nacional do Itatiaia. São Carlos. Tese de (Doutorado), Universidade de São Paulo, São Carlos, 1999.

22. MAGRO, T.C. Impactos ambientais de projetos de turismo rural. In: Turismo no espaço rural brasileiro. OLIVEIRA, C.G.S.; MOURA. J.C.; SGAI, M. (eds.) Piracicaba: Fundação de Estudos Agrários Luiz de Queiroz (FEALQ), USP, v. 1, p. 75-89, 2001.

23. MIDAGLIA, C.L.V. Turismo e meio ambiente no litoral paulista. São Paulo, 115p. Dissertação (Mestrado) - Faculdade de Filosofia, Letras e Ciências Humanas, Universidade de São Paulo, 1994.

24. MIGLIORINI, R.B. Hidrogeologia em Meio Urbano. Região de Cuiabá e Várzea Grande-MT. São Paulo: 145p. Tese de (Doutorado), Instituto de Geociências da Universidade de São Paulo, 1999.

25. MIGLIORINI, R.B; BARROS, M.S; APOETIA, L.F.M; SILVA, J.J.F. Diagnóstico Preliminar das principais províncias hidrogeológicas do Estado de Mato Grosso: uma proposta de mapa hidrogeológico de reconhecimento. Recursos Hídricos de Mato Grosso, FERNANDES, C.J e VIANA, R.R (eds). Universidade Federal do Mato Grosso, v.3, p. 37-50, 2006.

26. NPS - National Park Service. Visitor experience and resource protection implementation plan. Arches National Park. Denver, 1995.

27. OECD - Organization for Economic Co-Operation and Development. Environmental Indicators. Paris, 1994.

28. PORTAL DE MATO GROSSO. Disp.: http://www.matogrossoeseusmunicipios.com.br/

29. RUSCHMANN, D.V.M. Turismo no Brasil: análise e tendências. Barueri (SP): Manole, 2002.

30. SARDINHA, D.S.; CONCEIÇÃO, F.T.; CARVALHO, D.F.; CUNHA, R.; SOUZA, A.D.G. Impactos do uso público em atrativos turísticos naturais no município de Altinópolis (SP). Geociências, v. 26, n. 2, p. 161-172, 2007.

31. SIAGAS - Sistema de Informação de Águas Subterrâneas. (Base de dados na internet). Brasil: Companhia de Pesquisa em Recursos Minerais - CPRM. Serviço Geológico do Brasil. (Atualizado em maio de 2010). Disp. em: http://www.siagas.cprm.gov.br. Acesso em 17/04/2013

32. STANKEY, G.H.; COLE, D.N.; LUCAS, R.C.; PETERSEN, M.E.; FRISSEL, S.S. The limits of Acceptable Change System for wilderness Planning. USDA Forest Service, 1985.

33. TIAA - Travel Industry Association of America. Geotourism. The New Trend in Travel. Travel Industry Agency of America. 70pg., 2003.

34. TIES - The International Ecotourism Society. The International Ecotourism Society. Disponível em: $<$ http://www.ecotourism.org. Acesso em 09/2013.

35. ZANFELICE, T.; ETCHEBEHERE, M.L.; SAAD, A.R. Avaliação preliminar do potencial turístico do município de Rifaina (SP) e os impactos decorrentes do uso público de seus atrativos paisagísticos. Geociências, v. 28, n. 2, p. 203-220, 2009.

Manuscrito recebido em: 03 de Junho de 2016 Revisado e Aceito em: 15 de Agosto de 2016 